\title{
Creating goal scoring opportunities in elite soccer. Tactical differences between Real Madrid CF and FC Barcelona \\ Creación de ocasiones de gol en fútbol de élite. Diferencias tácticas entre Real Madrid CF y FC Barcelona
}

\author{
*Ignacio López Bondia, *Joaquín González-Rodenas, *Ferran Calabuig Moreno, **José Antonio Pérez-Turpin and *Rafael \\ Aranda Malavés \\ *University of Valencia (Spain), ${ }^{* *}$ University of Alicante (Spain)
}

\begin{abstract}
The aim of this study was to compare the playing tactics used to create scoring opportunities between Real Madrid C.F. (RMCF) and F.C. Barcelona (FCB). All team possessions which achieved scoring opportunity ( $\mathrm{n}=945)$ during 64 matches (32 per team) corresponding to the 2011-2012 Spanish BBVA League were analyzed through systematical observation. Possessions were grouped according to the start-up type of possession into «recoveries» $(\mathrm{n}=526)$, «restarts» $(\mathrm{n}=199)$, and «set-plays» $(\mathrm{n}=175)$. Multidimensional data from nine categorical variables related to playing tactics were analyzed using chi-square analysis. In recoveries, RMCF registered higher initial penetration $(p<0.01)$, higher percentage of counterattacks $(p<0.01)$, fewer passes $(p<0.01)$, higher percentage of penetrative passes $(p<0.001)$ and greater number of scoring opportunities outside the score pentagon $(\mathrm{p}<0.01)$ than FCB. In restarts, the single difference was that RMCF registered greater number of scoring opportunities outside the score pentagon than FCB $(p<0.001)$. The main differences between RMCF and FCB occurred in the transition between defense to attack, where RMCF was more penetrative immediately gaining the ball, progressed faster and used more frequently the counterattack. In contrast, FCB finished nearer the goal than RMCF.
\end{abstract}

Keywords: performance analysis, football, goal scoring, offensive play, notational analysis.

Resumen. El objetivo de este estudio fue comparar los indicadores tácticos utilizados en la creación de ocasiones de gol entre Real Madrid C.F. (RMCF) y F.C. Barcelona (FCB). Todas las posesiones finalizadas en ocasión de gol (n=945) durante 64 partidos (32 por equipo) de la Liga BBVA 2011-2012 fueron analizadas a través de observación sistemática. Las posesiones fueron agrupadas según el tipo de inicio en «recuperaciones» $(\mathrm{n}=526)$, «reanudaciones» $(\mathrm{n}=199)$, y «acciones a balón parado» ( $\mathrm{n}=175)$. 9 dimensiones relacionadas con indicadores tácticos fueron analizadas utilizando análisis chicuadrado. En recuperaciones, RMCF registró más penetración inicial $(\mathrm{p}<0.01)$, mayor porcentaje de contraataques $(\mathrm{p}<0.01)$, menor número de pases $(\mathrm{p}<0.01)$, más pases penetrativos $(\mathrm{p}<0.001)$, y mayor número de ocasiones de gol fuera del pentágono de finalización $(\mathrm{p}<0.01)$ que el FCB. En reanudaciones, la única diferencia fue el mayor número de ocasiones de gol fuera del pentágono de finalización del RMCF con respecto al FCB $(p<0.001)$. Las mayores diferencias entre RMCF y FCB tuvieron lugar en la transición entre el momento defensivo y el ofensivo, donde el RMCF fue más penetrativo inmediatamente después de recuperar el balón, progresando más rápido y usando con mayor frecuencia el contraataque. En cambio, el FCB finalizó sus ocasiones de gol más cerca de la portería rival que el RMCF.

Palabras clave: análisis de rendimiento, fútbol, ocasión de gol, juego ofensivo, análisis notacional.

\section{Introduction}

Performance analysis in competition is generally used to observe and assess teams and professional players. In this respect, notational analysis, which is a technique used for analyzing different aspects of performance through a process which involves producing a permanent record of the events (James, 2006), may provide important information for coaches and players in order to improve the training process (Borrie, Johnnsson \& Magnusson, 2002).

Over the last few years there has been a rise in the number of studies on match analysis in soccer which try to discover successful offensive game patterns through analysis of tactical variables during ball possessions. In this way, variables such as pass number (Hughes and Franks, 2005), type of start (Wright, Atkin, Polman, Jones \& Sargeson, 2011), type of attack (Armatas \& Yiannakos, 2010; Yiannakos \& Armatas, 2006) or opponent interaction (Lago-Ballesteros, Lago-Peñas \& Rey, 2012; Tenga, Holme, Ronglan \& Bahr, 2010) have been studied and associated with producing offensive success.

Similarly, although goal scoring is the main indicator of offensive success in soccer, it may not truly represent the underlying tactical strategies of a team, i.e., those that are concerned with the actual development of goal scoring opportunities (James, Mellalieu \& Hollely, 2002). For this reason, other offensive indicators have been used such as shots at goal (Pollard \& Reep, 1997), entries in the final third (Bate, 1988), penalty area (Ruiz-Ruiz, Fradua, Fernandez-Garcia \& Zubillaga, 2012), score box (Lago-Ballesteros et al, 2012; Tenga, Holme, Ronglan \& Bahr 2010a) or scoring opportunities (Wright, Atkins, Polman, Jones \& Lee 2011)

Fecha recepción: 15-11-16. Fecha de aceptación: 10-03-17 Ignacio López Bondia iglobon@gmail.com
With regards to goals, Armatas and Yiannakos (2010) observed in the 2006 World Cup that $47 \%$ were produced by organized attacks, $20.3 \%$ by means of counterattacks and $32.6 \%$ by set plays. Regarding shots at goal, Hughes and Franks (2005) observed that in the 1990 and 1994 Soccer World Cup Tournaments $80 \%$ and $77 \%$ of the shots at goal came from possession of 4 or less passes. Concerning goal scoring opportunities, Wright et al. (2011) analyzed 1788 goal scoring opportunities in the Premier League and observed that 65\% started by means of transition in play (interception, tackle and so on), $68 \%$ started in the attacking half, $85 \%$ had 4 or less passes and $53 \%$ finished inside the penalty area.

However, the use of aggregated data sets from many team performances potentially masks the factors that determine or contribute to each team's success or failure (Taylor, Mellalieu, James, \& Shearer, 2008). For this reason, the case studies of teams over a sustained period represent an appropriate approach to performance analysis in soccer and allow us to study the specific game model and tactical behaviors that characterize each team.

Therefore, in order to explore the specific tactical features required to create offensive success in selected top elite soccer teams, the aim of this study was to compare the playing tactics used to create scoring opportunities between Real Madrid C.F. (RMCF) and FC Barcelona (FCB) during the 2011-2012 Spanish BBVALeague.

\section{Materials and methodology}

\section{Sample}

A team possession finished with scoring opportunity was used as the basic unit of analysis according to the definition of Pollard and Reep (1997).

All team possessions which achieved scoring opportunity $(\mathrm{n}=945)$ during 64 matches (32 per team) corresponding to the 2011-2012 Spanish BBVA League were analyzed. Possessions which could not be viewed 


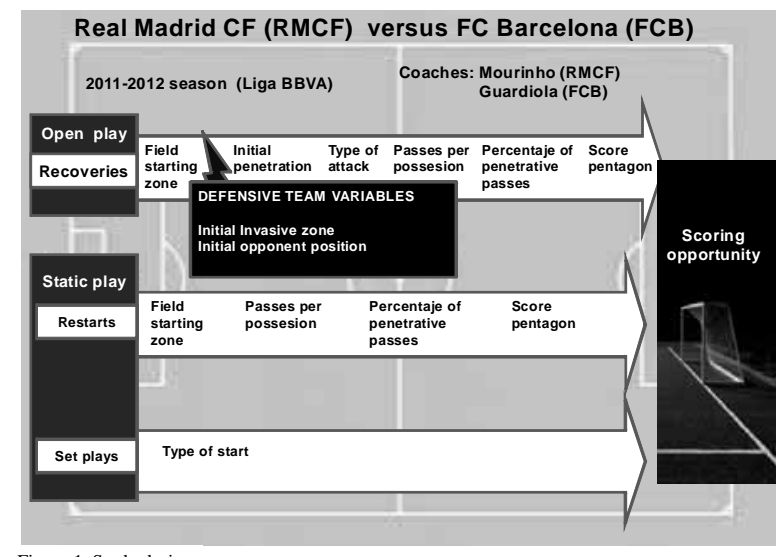

Figure 1. Study design

for retransmission reasons were excluded $(n=45)$. The selected possessions ( $\mathrm{n}=900$ ) were grouped depending on the startup type of possession into «recoveries» $(\mathrm{n}=526,58.4 \%)$, «restarts» $(\mathrm{n}=199,22.1 \%)$ and set-plays ( $\mathrm{n}=175,19.4 \%$ ), (Table 1). Matches were recorded in DVD from retransmissions on TV and they were played on the computer using the VLC Media Player software.

\section{Variables}

The study design (Figure 1) includes the analysis of multiple variables. For recoveries, six independent offensive variables (field starting zone, initial penetration, type of attack, passes per possession, percentage of penetrative passes and score pentagon) (Table 1) and two independent defensives variables (initial invasive zone and initial opponent position) were analyzed (Table 2). For restarts, four

Table 1.
Description and categories for offensive playing tactics (González-Rodenas, 2013)

Type of start-up possession: Way to start a team possession according to if the ball is in play or out of play. Three categories:

a. Recoveries: When a player gains possession of the ball by any means other than from a player of the same team with the ball in play.

- When a player restarts the game after a regulatory interruption:

b. Set-plays: 1) The restart takes place in the opponent 'half, 2) the tactical situation of the attacking team is prepared to try to shot at goal (Both teams group players into or just in front of the box and player positions change because some of the defenders move forward to try to shot at goal) and 3) the attacking team try to cross the ball into the box or shot at goal in one or two passes. (All corner kicks, all penalty kicks and those free kicks with the above characteristics are considered in this category).

c. Restarts: The restart takes place in any half, 2) the tactical situation of the attacking team is not prepared to try to shot at goal (player positions do not change) and 3) the attacking team try to pass the ball and build up a ball possession. (Goal kicks, free kicks, kick off, throw in).

Possession start

1. Field starting zone: Area of the playing field where team possession starts. Four areas were considered:

a.Defensive

b.Pre-defensive

c.Pre-offensive

d.Offensive (Score pentagon included)

2. Initial penetration: Degree of offensive directness in the first three seconds of the team

possession:

a. Penetrative action: Passes or dribbles towards the opponent 's goal past opponent player (s)

performed during the first three seconds of the ball possession.

b. Non-penetrative action: Any technical action towards any direction that does not past opponent player (s) performed during the first three seconds of the ball possession. Possession development

3. Type of attack: Degree of offensive directness (Bangsbo and Peitersen, 2000; Tenga et al., 2010: Lago Ballesteros et al., 2012) in the offensive process. Three categories were considered:

a. Combinative attack: 1) The possession starts by winning the ball in play or restarting the game, 2) the progression towards the opponent's goal has high percentage of no penetrative and short passes and long duration (evaluate qualitatively), as well as 3 ) this kind of possession allows the opponent to have more opportunity to minimize surprise, reorganize his system and be prepared defensively.

b. Counterattack: The possession starts by winning the ball in play, 2) the first or second player in action tries to penetrate using penetrative passes or dribbles, 3) the progressio towards the opponent's goal has high percentage of penetrative passes and short duration (evaluated qualitatively) as well as 3) this kind of possession tries not to allow the opponent to have opportunity to minimize surprise reorganize his system and be prepared defensively.

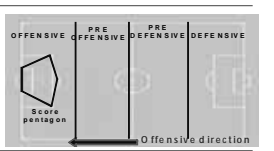

4. Passes per possession: Passes performed by players during team possession:

a. Short possession (3 or less passes) b. Mediun possession (4-6 passes) \& c. Long passession (7 or more passes)

5. Percentage of penetrative passes

Percentage of passes that past opponent player(s) in relation to the total number of passes during team possession: a. Low penetrating possession (0-33\%), b. Medium penetrating possession (34-66\%) \& c. High penetrating possession (67-100\%). independent offensive variables were evaluated (Field starting zone, passes per possession, percentage of penetrative passes and score pentagon) (Table 1). For set plays, one independent offensive variable was analyzed (type of start) (See tables 2 and 3). Finally, the variable scoring opportunity was used as an offensive indicator (Table 3).

\section{Match performance analysis}

The study was based on systematic observation (Anguera, et al., 2001) and it was nomothetic (several games) and multidimensional (the dimensions correspond with the criteria of the observation instrument). For the analysis, a soccer coach/researcher experienced in match performance analysed each possession post-event as many times as necessary using selected variables from the REOFUT observational instrument (González-Rodenas, 2013) (Table 1, 2 and 3). Asoccer coach/researcher with experience in match performance analyzed each possession postevent as many times as necessary. For analysis, a manual observational tool for the analysis of offensive performance in soccer was used (González-Rodenas, 2013). The reliability of data was calculated by the intra and inter-observer agreement (Cohen's Kappa) by analysing 54 random possessions before beginning the study (Inter-observer $\mathrm{k}$ value: from 0.725 to 0.944 ; and intra-observer $k$ value: from 0.839 to 0.972).

\section{Statistical analysis}

Data collected on paper were transcribed to a database created in SPSS 18.0 program (SPSS, Chicago, IL). A chi-square analysis was carried out to determine if there was an association between each independent variable and the rest of variables.

\section{Results}

\section{Descriptive analysis}

The average of scoring opportunities per team and match was 13.8 and 14.3 for RMCF and FCB, respectively.

Table 2 .

Description and categories for defensive variables (González Rodenas, 2013)

1. Initial opponent position: Opponent's height position on the field when team possession

a.Advanced: The opponent has the most backward player closer to the midline than to their own

a.Advance

b.Back: The opponent has the most backward player closer to their own goal line than the

b.Back:

midline.

2. Initial invasive zone: Area within the space of
defensive occupation (SDO) of the opponent according

to Seabra and Dantas (2006) where team possession to Seab

a.Non- invasive zone: The possession starts between the

first defender (nearest opposing player from the offensive team goal line) of the opponent's SDO and the own goal line.

b.Invasive zone: The possession starts between team the first defender of the opponent's SDO (nearest opposing player from the offensive team goal line) and the opposing goal line.

Wosive zone. The possession starts between in the area where is possible to face directly the back line line of defenders.

Table 3.

Description and categories for the variable "Possession outcome” (González Rodenas, 2013) Possession outcome: Degree of offensive success of the possession. (Score pentagon is used as a zone of reference because it selects the space with high shooting angle and short distance to goal (20 meters or less) which are very important factors to achieve goals (Pollard and Reep, 1997; Ensum, et al., 2005).

a.Scoring opportunity: The team has a clear chance of scoring a goal during team possession. This include:

-All shots produced inside the score pentagon and those shots produced outside the score pentagon and pass near the goal (2 meters or less with respect to the goal).

-All chances of shooting inside the score pentagon (The player is facing the goal, there is not any opponents between him and the goal and he has enough space and time to make a playing decision)

-Goals are included as a scoring opportunity.

b. No scoring opportunity: the team has any chance of scoring goal during team possession.

Table 4

Start-up type

\begin{tabular}{|c|c|c|c|c|c|}
\hline ort up type & $\begin{array}{c}\text { RMCF } \\
(\mathrm{n}=441)\end{array}$ & FCB $(n=459)$ & Percentage & $\mathrm{X}^{2}$ & $\mathrm{p}$ \\
\hline Recoveries & 263 & 263 & $58.4 \%$ & & \\
\hline Restarts & 80 & 119 & $22.1 \%$ & 9,807 & 0,007 \\
\hline Set-plays & 98 & 77 & $19.5 \%$ & & \\
\hline
\end{tabular}


The most start-up type of possession used by RMCF was recoveries ( $\mathrm{n}=263)$, followed by set-plays $(\mathrm{n}=98)$ and finally restarts $(n=80)$ (Figure 1). FCB also used often recoveries $(n=263)$, but the second start-up type of possession used was restarts $(\mathrm{n}=119)$ and finally set-plays (n=77) (see Table 4).

\section{Recoveries}

At the beginning of the possessions, RMCF registered greater initial penetration than FCB $(\mathrm{p}<0.01)$. There were no significant differences between both teams in the variables field starting zone, initial invasive zone and initial opponent position (Figures 2-5).

Regarding the development of possessions, RMCF had higher percentage of counterattacks $(\mathrm{p}<0.001)$, fewer number of passes per possession $(p<0.01)$, higher percentage of penetrative passes $(p<0.001)$ than FCB (Figures 6-8). At the end of the possession, RMCF registered lower percentage of scoring opportunities inside the score pentagon than FCB $(\mathrm{p}<0.01)$ (Figure 9).

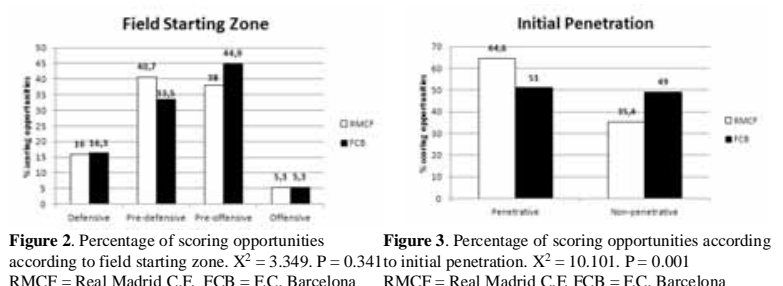

$\mathrm{RMCF}=$ Real Madrid C.F. FCB = F.C. Barcelona $\quad \mathrm{RMCF}=$ Real Madrid C.F. FCB = F.C. Barcelo

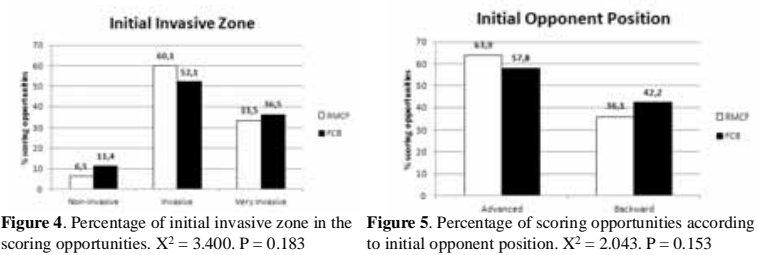
$\begin{array}{ll}\text { scoring opportunities. } X^{2}=3.400 . P=0.183 & \text { to initial opponent position. } X^{2}=2.043 . P=0.153 \\ \text { RMCF }=\text { Real Madrid C.F. FCB }=\text { F.C. Barcelona } & \text { RMCF }=\text { Real Madrid C.F. FCB }=\text { F.C. Barcelona }\end{array}$

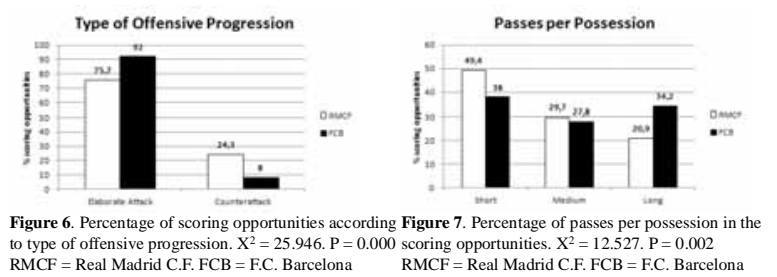

to type of offensive progression. $X^{2}=25.946 . P=0.000$ scoring opportunities. $X^{2}=12.527 . P=0.002$
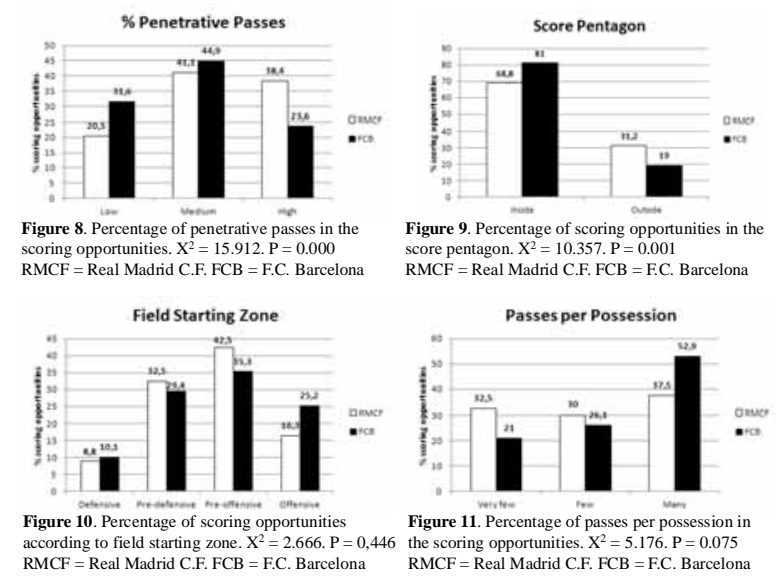

\section{Restarts}

There were no significant differences ( $p>0.05$ ) between RMCF and FCB in variables related to the beginning and development of the possession (Figures 10-12). Otherwise, at the end of the possession RMCF registered lower percentage of scoring opportunities inside the score pentagon $(\mathrm{p}<0.001)$ (Figure 13).

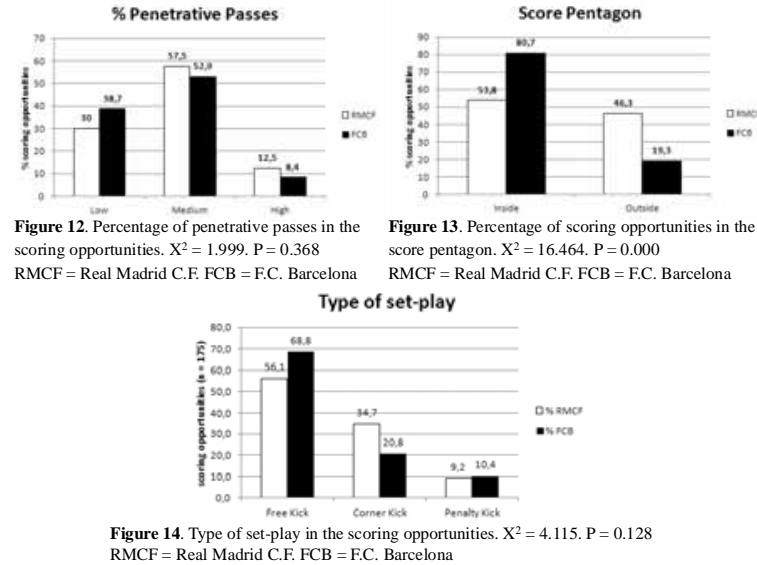

Set-plays

There were no significant differences between RMCF and FCB in the type of set-play $(\mathrm{p}>0.05)$. Both teams produced scoring opportunity through free kick, followed by corner kick and fewer times had a penalty kick chance (Figure 14).

\section{Discussion}

The aim of this study was to compare the playing tactics used to create scoring opportunities between RMCF and FCB during the 20112012 Spanish BBVALeague.

Regarding possessions which started after ball recovery, it is interesting to highlight that no significant differences between teams were found regarding the initial starting zone, initial invasive zone and initial opponent position. For both teams, the beginning of the possession took place in pre-defensive and pre-offensive zones, against an opponent in an advanced position and having a high proportion of ball recoveries in invasive zones of the opponent. These results indicate the importance of regaining the ball when the opponent is in an advanced position, as well as starting in invasive zones of the opponent's space of defensive occupation in order for both teams to create scoring opportunities. Despite both teams regaining the ball in similar spatial and opposing conditions, the initial tactical behavior was very different between them since RMCF showed a greater percentage of initial penetration than FCB. This means that RMCF progressed as soon as they gained the ball while FCB preferred to retain the ball possession instead of making penetrating passes towards the goal. In relation to this, RMCF progressed more frequently by means of counterattack, using fewer passes and making a higher percentage of penetrative passes per possession than FCB. These tactical characteristics highlight the differences between both game models since the strategy of RMCF was based on penetrating and reaching the goal as soon as possible, trying to take advantage of the space that the other team had left while they tried to attack. This fact would indicate that they try to make the most of their fast and explosive players, who would need space to use their speed and technique. However, FCB more often preferred to retain the ball possession and not to penetrate as soon as they gained the ball, trying to make a greater quantity of passes and elaborating ball possession more patiently.

Concerning «restarts» of play, no differences were found between both teams at the beginning and development of the possession. These results may be due to that fact that restarting play is tactically more predictable and the defensive team has more time to re-organize and get ready for the defensive moment, decreasing the options to surprise the opponent. This makes it difficult to penetrate quickly and would make it advisable to elaborate the ball possession. In fact, both teams used greater percentage of possessions with seven or more passes (RMCF: 37.5\%; FCB: 52.9\%) to create scoring opportunities. 
As far as the end of the possession is concerned, FCB was more penetrative than RMCF both in restarts and recoveries because they managed to finish a higher proportion of scoring opportunities inside the score pentagon, which is a selected space with a high shooting angle and short distance to the goal (20 meters or less). It is interesting to observe how RMCF was more penetrative at the beginning and during the possession development but FCB had more scoring opportunities nearer the goal than RMCF. This fact may be due to several factors. On the one hand, the style of play of FCB based on combinational play and combinative players, tried to elaborate and finish as near the goal as possible. On the other hand, the style of play of RMCF based on quick possessions and fast players may lead to difficulties to penetrate on a well organized team situated in a back position, what may have made recommendable to shoot from long distances.

Respecting set-plays, both teams mostly achieved scoring opportunities by means of free kicks, which shows that they have players with excellent ability to kick the ball when there is a free kick near the goal. It is worth mentioning that RMCF achieved a higher percentage of scoring opportunities by corner kicks than FCB although this difference is not statistically significant.

Comparing the results of the present study with previous literature, the present study shows that recoveries achieved a higher percentage of scoring opportunities (58.4\%) than restarts (22.1\%) and set plays (19.5\%). In accordance with these results, González-Rodenas (2013) observed that $56.4 \%, 23.6 \%$ and $20 \%$ of scoring opportunities in the 2010 World Cup were achieved by means of recoveries, restarts and set-plays, respectively. Similarly: Wright et al (2011) observed that $65 \%$ of scoring opportunities started by means of transition in play in the Premier League. On the other hand, previous research has suggested that set plays account for approximately one third of all goals scored (Armatas \& Yiannakos 2010; Bangsbo \& Peitersen 2000; Yiannakos \& Armatas, 2006) although the methodology of these latter studies did not take into account the differences between restarts and strategic set plays as the present study has considered.

On the other hand, the present study shows that both teams frequently started ball possessions in pre-defensive and pre-offensive zones. In this case, Lago-Ballesteros et al. (2012) found that a greater proportion of score-box possessions started recovering the ball in predefensive and pre-offensive zones. Futhermore, other studies found that over half of the scoring opportunities (Tenga et al., 2010), goal scoring (Tenga et al., 2010b) and score box possessions (Tenga et al., 2010a) started at the middle third of the field.

In terms of passing sequences, the majority of ball possessions performed by RMCF and FCB had 4 or more passes excluding setplays, which is not in accordance with previous literature that had observed that more shots and goals were indeed produced from shorter passing sequences than from longer ones (Bate, 1988; Franks, 1988, Hughes and Franks, 2005; Wright et al., 2011). However, it has been demonstrated that successful teams usually have longer ball possessions than other teams to shoot at goal (Hughes \& Franks, 2005) and score goals (Tenga \& Sigmundstand, 2011). Likewise, it makes sense that RMCF and FCB use longer possessions than the rest of the teams because the technical ability of their players is most probably higher than the average ability of teams analysed in previous studies.

As for the type of attack, both teams used mainly elaborate attack to reach the goal, but RMCF used a higher percentage of counterattacks (24.3\%) than FCB (8.0\%). Additionally, previous studies found that counterattacks occurred less frequently than organized offences in goals scored during the 2006 World Cup (Yiannakos \& Armatas, 2006) and the 2004 European Championship in Portugal (Armatas \& Yiannakos 2010). These studies (although they are based on goal scoring) observed how counterattacks created around $20 \%$ of the goals scored, which is slightly lower than the percentage used by RMCF but much higher that the percentage used by FCB. According to these studies, it is even surprising the low proportion of counterattacks that FCB carried out during the 2011-2012 season compared to RMCF.
At the end of the possession, FCB managed to achieve scoring opportunities nearer to the goal than RMCF (Recoveries: $81.0 \%$ vs $68.8 \%$ and restarts: $80.7 \%$ vs $53.8 \%$, respectively). It is worth highlighting the high percentage of shots performed by RMCF outside the score pentagon, especially in restarts. The fact that during restarts RMCF could not use the counterattack and the opponent might have been more organized defensively could require shooting from farther distances to try to score goals. The highly-skilled players that RMCF had in terms of shooting may have influenced this tactical indicator. Other studies, such as the study of Yiannakos and Armatas (2010), used the penalty area instead of the score pentagon to measure this tactical indicator, which calculated that $79.6 \%$ of goals were scored from the penalty area at the 2004 European Championship in Portugal while $35.2 \%$ were achieved from not further than $5.5 \mathrm{~m}$. Also, Durlik and Bienek (2014) observed that $85 \%$ of shots ocurred inside the penalty area. In accordance with Clemente (2012), the most successful teams at international events finish most of their offensive attacks from the penalty area which may indicate polished strategy in positional and counter attack.

With regards to the limitations of this study, the analysis of two single elite teams reflects only the particular style of play of these teams, so care should be taken when extrapolating these results to other teams and contexts. However, this study represents a way to analyse the game model that can be applied by coaches in their teams in order to create specific methodology of training (Vales-Vázquez, Areces-Gayo, Arce-Fernández \& Torrado-Quintela, 2017) by designing tactical situations similar to the competition (Serra Olivares \& Garcia Rubio, 2017) that may include the performance indicators that are relevant to achieve offensive success in elite soccer games.

\section{Conclusions}

The beginning and development of those possessions that created scoring opportunities by Real Madrid CF and FC Barcelona during 2011-2012 Spanish BBVA League were different only when there was transition between defense and attack since Real Madrid CF played with more initial penetration, more proportion of counterattacks, fewer passes and more percentage of penetrative passes than FC Barcelona. At the end of the possessions, FC Barcelona had higher percentage of scoring opportunities near the goal than Real Madrid CF.

\section{References}

Anguera, M.T, Blanco-Villaseñor, A. \& Losada, J.L. (2001). Diseños observacionales, cuestión clave en el proceso de la metodología observacional. Metodología de las Ciencias del Comportamiento, 3, 135-161.

Armatas, V., \& Yiannakos, Á. (2010). Analysis and evaluation of goal scored in 2006 world cup. Journal of Sport and Health Research, 2(2), 119.

Armatas, V., Ampatis, D., \& Yiannakos, A. (2005). Comparison of the effectiveness between counter-attacks and organized offences in Champions League2002-03. 1st International Scientific Congress in Soccer, pp. 8-10. April, Trikala: Greece.

Bangsbo, J., \& Peitersen, B. (2000). Soccer systems and strategies. Champaign, IL: Human Kinetics.

Barbosa, A., Martins, N., Leitão, J., Sarmento, H., \& Campaniço, J. (2011). Temporal interaction patterns in the offensive process in the spanish league 2010/2011 season. British Journal of Sports Medicine, 45(15), A9-A9.

Bate, R. (1988). Football chance: Tactics and strategy. In T. Reilly, A. Lees, K. Davis, \& W. Murphy (Eds.), Science and football (pp. 293-301). London: E. \& F.N. Spon.

Borrie, A., Jonsson, G, \& Magnusson, M. (2002). Temporal pattern analysis and its applicability in sport: an explanation and exemplar data. Journal of Sports Sciences, 20, 845-852. 
Clemente F.P. (2012). Study of successful soccer teams on Fifa World Cup 2010. Pamukkale Journal of Sports Sciences, 3(3), 90-103.

Dufour, W. (1993). Computer-assisted scouting in soccer. In T. Reilly, J. Clarys, and A. Stibbe (Eds.), Science and Football II (pp. 160166). London: E. \& F.N. Spon.

González-Rodenas, J. (2013). Análisis del rendimiento táctico en el juego colectivo ofensivo en fútbol en la copa del mundo 2010. Universidad de Valencia (Tesis Doctoral)

Gréhaigne, J. (2001). La organización del juego en el fútbol (1st ed.) Barcelona: INDE, 2001.

James, N. (2006). Notational analysis in soccer: past, present and future. International Journal of Perfomance Analysis in Sport, 6(2), 67-81.

James, N., Mellalieu, S., and Hollely, C. (2002). Analysis of strategies as a function of European and Domestic competition. International Journal of Performance Analysis in Sport, 2, 85-103.

Krzysztof, D., \& Pawet, P. (2014). Analysis of goals and assists diversity in English Premier League. Journal of Health Sciences, 04(05), 047-056.

Lago Ballesteros, J., Lago, C., \& Rey, E. (2012). The effect of playing tactics and situational variables on achieving score-box possessions in a professional soccer team. Journal of Sports Sciences, 30(14), 1455-1461.

McGarry, T., \& Franks, I. M. (2003). The science of match analysis. In T. Reilly, \&A.M. Williams (Eds.), Science and soccer, $\left(2^{\text {nd }} \mathrm{ed}\right.$., pp. 265-275). London: Routledge.

Olsen, E., \& Larsen, O. (1997). Use of match analysis by coaches. In T. Reilly, M. Hughes, \& J. Bangsbo (Eds.), Science and football III (pp. 209-222). London: E. \& F.N. Spon.

Pollard, R., \& Reep, C. (1997). Measuring the effectiveness of playing strategies at soccer. Journal of the Royal Statistical Society: Series D (The Statistician), 46(4), 541-550.

Ruiz-Ruiz, C., Fradua, L., Fernández-García, A., \& Zubillaga, A. (2011). Analysis of entries into the penalty area as a performance indicator in soccer. European Journal of Sport Science. doi:10.1080/ 17461391.2011.606834.
Seabra, F., \& Dantas, L. (2006). Space definition for match analysis in soccer. International Journal of Performance Analysis in Sport, 6(2), 97-113.

Serra-Olivares, J., Garcia-Rubio, J. (2017). La problemática táctica, en el diseño de tareas desde el enfoque de la pedagogía no lineal aplicada al deporte. Retos, 32, 261-269.

Taylor, J., Mellalieu, S., James, N., \& Shearer, D. (2008). The influence of match location, quality of opposition, and match status on technical performance in professional association football. Journal of Sports Sciences, 26(9), 885-895.

Tenga, A., Holme, I., Ronglan, L. T., \& Bahr, R. (2010a). Effect of playing tactics on achieving score-box possessions in a random series of team possessions from Norwegian professional soccer matches. Journal of Sports Sciences, 28(3), 245-255.

Tenga, A., Holme, I., Ronglan, L. T., \& Bahr, R. (2010b). Effect of playing tactics on goal scoring in Norwegian professional soccer. Journal of Sports Sciences, 28(3), 237-244.

Tenga,A., Ronglan, L. T., \& Bahr, R. (2010). Measuring the effectiveness of offensive match-play in professional soccer. European Journal of Sport Science, 10(4), 269-277.

Tenga, T \& Sigmundstad, E. (2011). Characteristics of goal-scoring possessions in open play: Comparing the top, in-between and bottom teams from professional soccer league. Journal of Performance Analysis in Sport, 11, 545-552.

Vales-Vázquez, A., Areces-Gayo, A., Arce-Fernández, C., \& TorradoQuintela, J.(2017). Comparación del grado de especificidad de dos microciclos de entrenamiento en fútbol correspondientes a un equipo profesional y a un equipo en formación. Retos, 32, 14-18.

Wright, C., Atkins, S., Polman, R., Jones, B., Lee S. (2011). Factors Associated with Goals and Goal Scoring Opportunities in Professional Soccer. International Journal of Performance Analysis in Sport, 11(3), 438-449.

Yiannakos, A., \& Armatas, V. (2006). Evaluation of goal scoring patterns in the European Championship in Portugal 2004. International Journal of Performance Analysis in Sport, 6, 178-188.

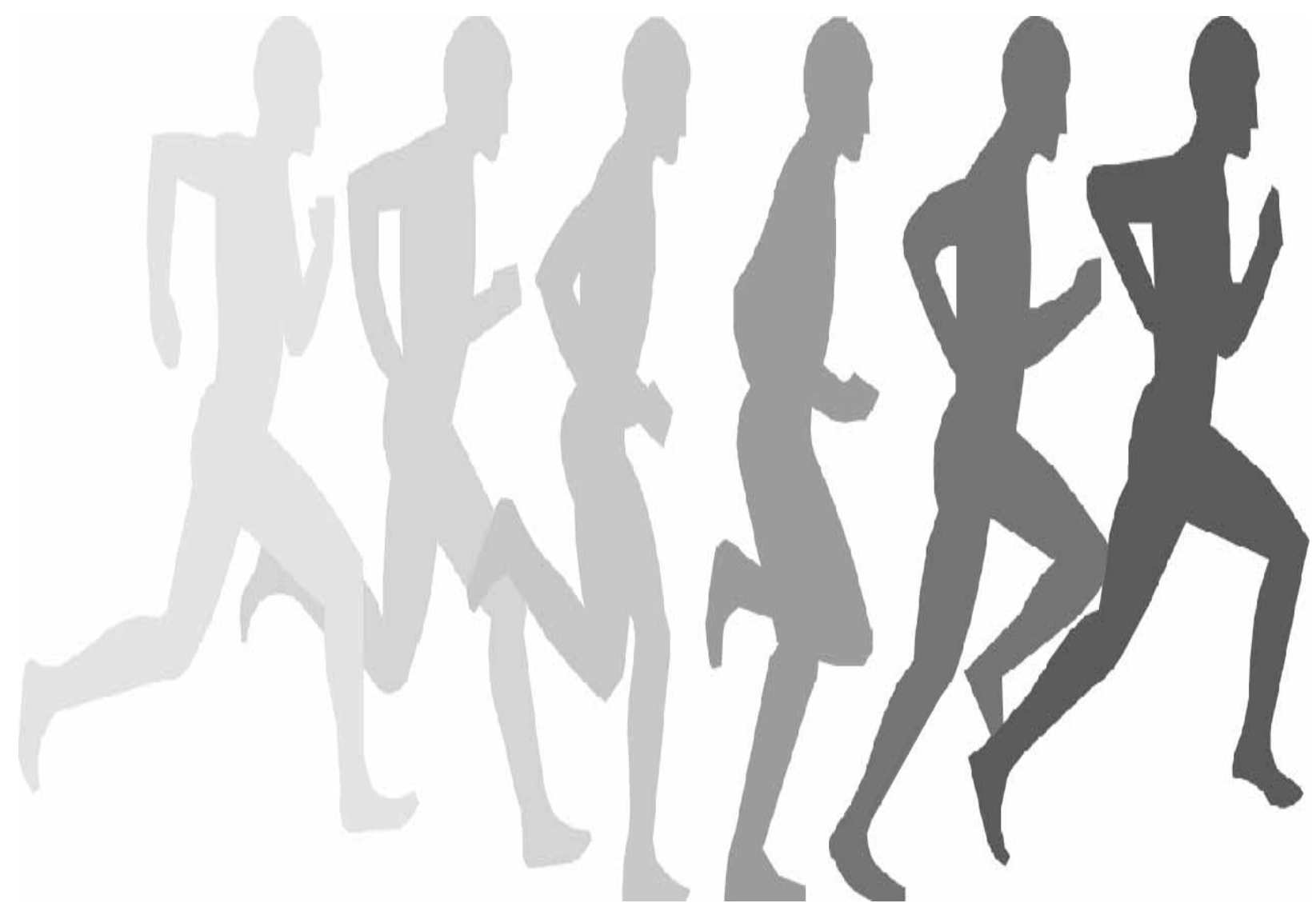

